\title{
O Incorpóreo da Imagem como Dispositivo Háptico
}

\author{
Adriani Ferreira de Araujo - Mestranda - PPGAV UFRGS \\ adrianiaraujo@gmail.com \\ Eduardo Figueiredo Vieira da Cunha - Orientador - PPGAV UFRGS \\ ecunha@cpovo.net
}

\begin{abstract}
RESUMO
O presente trabalho compõe o início de uma pesquisa de mestrado. Ela busca compreender as particularidades incorpóreas da imagem em vídeo e em fotografia, provenientes de uma produção em artes visuais, que se constitui no aprofundamento de estudo anterior sobre a matéria informe (massa de pão crua) em sua condição viscosa. As questões que serão apresentadas abrangem um primeira reflexão de como tais imagens podem ser apreendidas como um dispositivo háptico na sua intrínseca incorporalidade não táctil. O material em estudo baseia-se em um vídeo e fotografias de uma produção própria. Material este, analisado a partir de uma interlocução entre o conceito de háptico, pela questão fenomenológica do corpo e dos sentidos na contemporaneidade e por uma materialidade que se oculta pela ausência dos corpos nos meios digitais.
\end{abstract}

Palavras-chave: imagem; háptico; incorpóreo; matéria; viscoso.

\section{INTRODUÇÃO}

O presente trabalho compõe o início de uma pesquisa de mestrado. Ela busca compreender as particularidades incorpóreas da imagem em vídeo e em fotografia, provenientes de uma produção em artes visuais e que se constitui no aprofundamento de estudo que tratava inicialmente sobre os comportamentos da matéria informe ${ }^{1}$ (massa de pão), a partir de 2010, durante a graduação. Este estudo, atualmente avança, para as questões da condição viscosa da matéria por uma leitura da imagem.

\footnotetext{
${ }^{1}$ Verbete criado por Georges Bataille e publicado em seu Dicionário Crítico na revista Documentos (BATAILLE, 1969, p.145).
} 
Dentro desta perspectiva de condição da matéria surge um recorte que será aqui apresentado, sobre o trânsito entre matéria corpórea que se apresenta na espacialidade e a imaterialidade incorpórea que se apresenta no vídeo e na fotografia como resultado final. Para isso, as questões que serão apresentadas abrangem um primeira reflexão de como tais imagens podem ser apreendidas como um dispositivo háptico na sua intrínseca incorporalidade não táctil.

Conceitualmente, a ideia de dispositivo háptico apresenta uma mudança de paradigma, atribuindo ao óptico uma condição tátil em contraposição a este distanciamento entre tato e imagem digital, e retoma assim, a fenomenologia do corpo e dos sentidos nas imagens, quando estas tecnicamente, apresentam uma ausência do corpo.

Sobre o vídeo e a fotografia, eles fazem parte de um processo de capturas e registros necessários dentro de uma produção calcada pela efemeridade da matéria usada. Neste caso, a massa de pão crua. Estes meios de apresentação do trabalho, para além do espacial, são modos de fazê-los existir por dois motivos: o primeiro pela característica pulsante da matéria que respira e leveda - são diversos os estágios que se revelam com o tempo de crescimento da massa -, e o segundo motivo é pela inexistência do trabalho subsequente à montagem. Este, certamente poderá ser refeito, porém, aquele que já aconteceu nunca mais será possível fazer igual. E é neste enfrentamento com relação ao desaparecimento do trabalho, que surge o vídeo e a fotografia. Primeiramente surge como um registro em meio ao processo, e em seguida, passa a compor com frequência a própria produção.

No contexto teórico haverá uma interlocução sobre a fenomenologia da percepção de Maurice Merleau-Ponty e sobre a teoria das imagens tecnológicas da autora portuguesa Patrícia Silveirinha Castello Branco que aborda a função háptica por uma particularidade tátil possível de ser captada pelo mecanismo óptico.

Em seguida o texto apresentará as relações conceituais com trabalhos em vídeo e fotografia. O material que será apresentado para o estudo baseia-se em registro de um vídeo e fotografias de produção própria trazendo suas peculiaridades sobre percepção e sentidos, háptico e corpo. 
Portanto, este é o primeiro estágio desta pesquisa que pretende resgatar um sentimento no vídeo e na fotografia que são tecnicamente incorpóreos. Resgatar pela imagem, os sentidos e também um corpo que, de algum modo, se anula quando capturado ou apresentado nos meios digitais. Como é possível expandir o estudo sobre a matéria, se no produto final ela inexiste? A mudança de parâmetro para o virtual provoca esta abordagem e um pensamento sobre memória e desmemoria de um corpo/matéria.

\section{O Corpo e o Sentido}

O sentido pode ser pensado por uma sensação que está no meio, entre uma coisa ou outra. Um não limite entre o material e o imaterial. Mas, se os sentidos relacionados ao corpo materializado se justificavam por sua presença, o que é feito do sentido em sua ausência? Para esta resposta se faz necessária uma primeira abordagem sobre as questões da Fenomenologia da Percepção de Maurice Merleau-Ponty calcada na filosofia e que apresenta a ideia de um corpo com sentidos e predisposto a estímulos que, pelo estudo sobre os sentidos, não é possível separar o perceptor da coisa percebida. Das análises sobre percepção, existem outras tantas abordadas por diversos autores que trazem questões sobre o sujeito, a ciência, a política ou questões sociais. Mas é à percepção dos sentidos que este trabalho pretende se deter.

Segundo este estudo filosófico, existem os estímulos objetivos e os subjetivos. $\mathrm{O}$ objetivo trata do estímulo direto do sentido, o subjetivo trata do estímulo indireto do sentido. Este segundo é o estímulo que interessa para esta pesquisa, pois ele vai orientar a reflexão e o trânsito do conceito fenomenológico para a contemporaneidade. Para o autor, o estímulo subjetivo se difere do objetivo por estar atrelado à uma sensação e por isso, renuncia totalmente definir a sensação apenas pela impressão pura. "Neste caso, portanto, 'o sensível' não pode mais ser definido como o efeito imediato de um estímulo exterior" (MERLEAU-PONTY, 2011, p. 29). Esta frase indica que algo está mediando a relação entre o perceptor e o que é percebido, neste caso, portanto é o sentido. E ainda indica, que "O sentir é esta comunicação vital com o mundo que o torna presente para nós como lugar familiar de nossa vida. É a ele que o objeto percebido e o sujeito que percebe devem sua espessura" (MERLEAU-PONTY, 2011, p. 84). 
É possível apreender que a subjetividade do sentido abre uma possibilidade para que se perceba o corpo como um todo em si, pois ele é autônomo no que tange às sensações por ser do mundo tanto quanto as outras coisas. Nesta direção, o autor nos faz entender o corpo como integrante no espaço, pois ele está neste lugar, para que seja possível um corpo pensado não por fragmentos perceptivos, mas pela sua completude que, em si, codifica as percepções de tudo.

\begin{abstract}
Não completamos apenas as relações entre os segmentos do nosso corpo e as correlações entre corpo visual e corpo tátil: nós mesmos somos aquele que mantém em conjunto estes braços e pernas, aquele que ao mesmo tempo os vê e os toca. O corpo é, para retomar a expressão de Leibniz, a 'lei eficaz' de suas mudanças. Se ainda se pode falar, na percepção do corpo próprio, de uma interpretação, seria preciso dizer que ele se interpreta a si mesmo. Aqui, os 'dados visuais' só aparecem através de seu sentido visual, cada movimento local sobre o fundo de uma posição global, cada acontecimento corporal, qualquer que seja o 'analisador' que o revele, sobre um fundo significativo em que suas ressonâncias mais distantes estão pelo menos indicadas e as possibilidades de uma equivalência intersensorial está imediatamente fornecida. O que reúne as 'sensações táteis' de minha mão e as liga às percepções visuais da mesma mão, assim como as percepções dos outros segmentos do corpo, é um certo estilo dos gestos de minha mão, que implica um certo estilo de movimento de meus dedos e contribui, por outro lado, para uma certa configuração de meu corpo (MERLEAU-PONTY, 2011, p. 208).
\end{abstract}

E a partir da ideia de que o corpo interpreta a si mesmo, neste estágio a pesquisa tenta elaborar como se dão os sentidos quando da ausência do corpo, especificamente no caso das imagens tecnológicas. Como é possível manter as sensações táteis quando a coisa percebida é digital e, portanto, a relação se dá objetivamente pelo olhar? Justamente, é com esta objetividade atribuída rigorosamente ao olhar, que a pesquisa tenta romper, com a intenção de aprofundar as questões da condição da matéria informe. É possível fortalecer esta ideia de ruptura pelo conceito sobre o háptico, ou seja, uma possível percepção ativa que é captada pelo olho, mesmo que o perceptor não toque. A função háptica é uma função tátil de outra ordem, de uma ordem subjetiva e que portanto estuda o sentir através da imagem. 


\title{
O Háptico como Percepção Ativa
}

Para esta abordagem parte-se da tese que originou o livro da investigadora portuguesa Patrícia Castello Branco, ela elabora um pensamento no que tange às relações do corpo com a imagem tecnológica, por uma ordem crítica de como a arte submeteu a imagem ao regime ocular, anulando assim, qualquer relação com outros sentidos do corpo.

\begin{abstract}
A grande mudança pode ser resumida no facto de o conceito de imagem como entidade autónoma, distante e separada desaparecer para dar lugar a um ideal de espaço envolvente. As novas imagens e as novas formas de arte retiraram a imagem da tela e a jogam principalmente com a ideia de vivência, de ambiência, de envolvência e de textura, mas também de perturbação sensorial através da introdução de inputs das mais variadas origens e natureza: imagens fotográficas, imagens digitais, cinema, ecrãs de variadas formas, sons texturas e até cheiros substituem o próprio objeto visual. O que parece estar em causa é o agenciamento das sensações, não exclusivamente visuais, mas tendencialmente hápticas. Os sentidos são abalados, questionados, surpreendidos nas suas coordenadas espácio-temporais que, por sua vez são destabilizadas ou reconfirmadas, alteradas e reconstruídas através do sentido da visão, do tacto, do cheiro, do equilíbrio. Transformação, instabilidade são o emblema desta nova ordem perceptiva (CASTELLO BRANCO, 2013, p. 495).
\end{abstract}

Falar em háptico é se referir a um sentir através da imagem que se instaura pelo óptico, portanto, o óptico ao mesmo tempo que estabelece uma oposição por ser um sentido objetivo - como trata Merleau-Ponty -, também estabelece uma complementação ao entendimento do que seja o háptico, pois é pelo óptico que chegamos à esta percepção ativa e tátil. É por meio deste dispositivo que subjetivamente tocamos a imagem, sem que ela perca a sua capacidade corpórea. Como exemplo para este entendimento, partir do próprio processo artístico é um caminho, devido às constantes variações entre materialidade e imaterialidade e também em razão do alojar e desalojar dos sentidos.

Em meu trabalho artístico estas extremidades são bastante recorrentes devido ao lugar onde disponho a massa de pão crua. Ela está no plano físico e ela acontece numa realidade quase escultórica e torna-se tão viva e material que é necessário um tempo de distanciamento entre a gravação ou os processos fotográficos, para posteriormente pensá-los como edição e finalização. Este tempo se faz necessário para que seja possível educar o meu sentido para a suposta imaterialidade que precede no trabalho. Como foi 
dito na apresentação deste artigo, o meio tecnológico nesta produção artística, se faz necessária pela efemeridade da matéria, portanto, um constante enfrentamento com o desparecimento corpóreo do trabalho.

O vídeo Casa Velha, 1980-2016 é uma busca pela recomposição da memória de anos que a distancia do agora. Um resgate por fragmentos, pela ruína e pela fotografia analógica de um lugar onde nada mais habita, apenas a lembrança. Devido aos trinta e seis anos passados, o vídeo inicia com uma característica de registro por meio de imagens que perpassam estes anos, em meio a sons que são igualmente referentes às memórias ativadas. Num segundo momento, o vídeo passa a se compor por transições entre imagens da casa atual filmada e imagens fotográficas filmadas com uma sobreposição de camada de massa de pão crua, que provoca uma espécie de preenchimento sobre uma parede de tijolos.

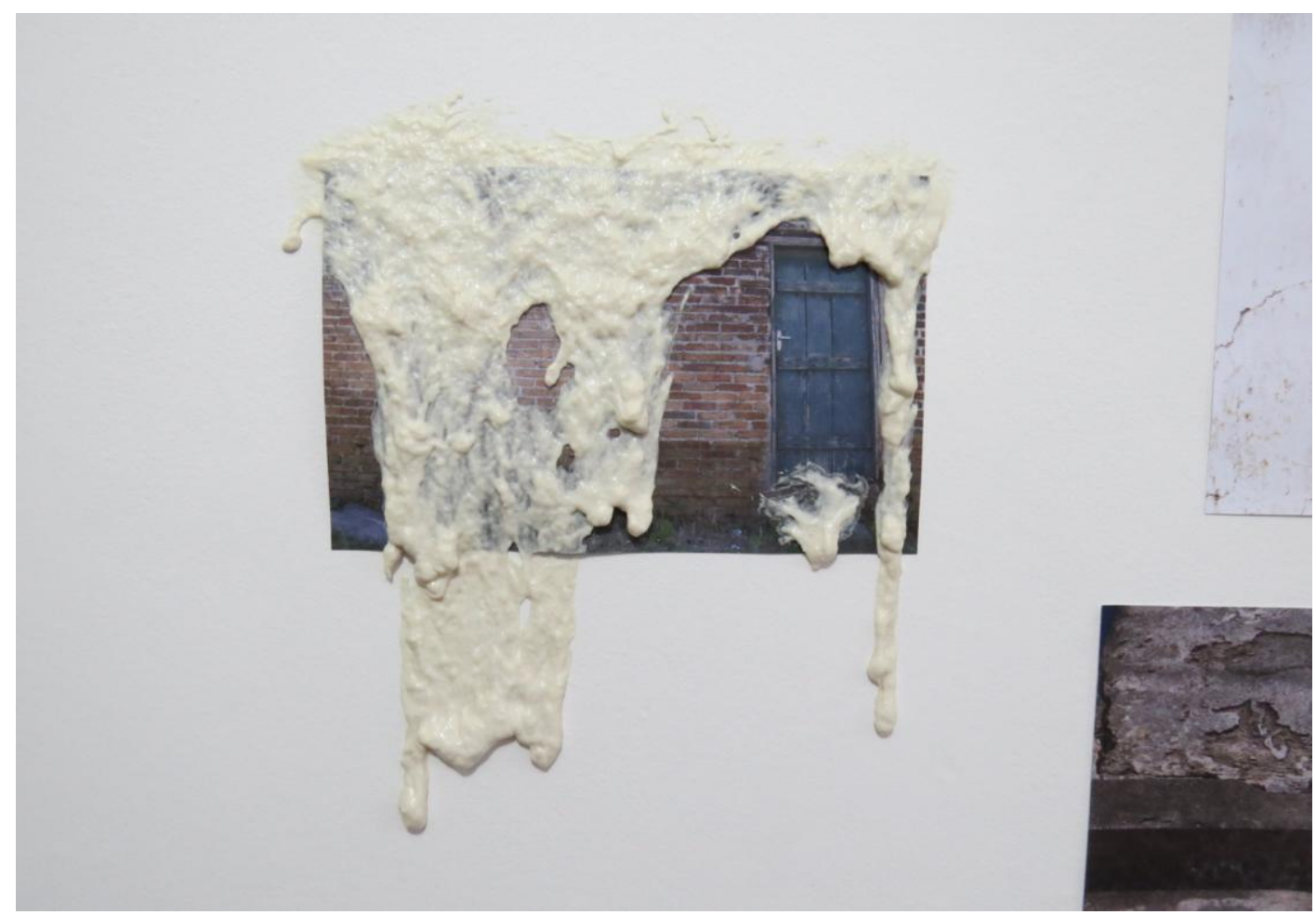

Figura1: Registro na ambiência da filmagem - massa sobre fotografia impressa a laser em folha A4. Fonte: acervo digital da artista.

Neste momento, a fotografia filmada continua com sua característica estática. O que se move é a matéria, que pela condição viscosa, se adere à superfície estabelecendo um contato tátil entre corpo informe e corpo fotográfico. A atmosfera que se cria no 
vídeo é de outra instância que a do registro, pois está inserida no contexto temporal da imagem movimento.

Já nas imagens seguintes, que são fotografias, a relação da matéria com o corpo que ela toca não é móvel, mas cria uma espessura que não nega o tátil. Existe uma aderência da matéria ao corpo ou ao objeto que exalta a apreensão dos olhos, uma retomada ao corpóreo. Nesta dualidade entre material e imaterial surge uma nova questão acerca do estímulo sensorial entre processo e vídeo final, e entre o processo performático da matéria e fotografia capturada. Que estímulo é este, nesta produção aqui apresentada, que possibilita uma retomada dos sentidos pelo conceito de háptico?

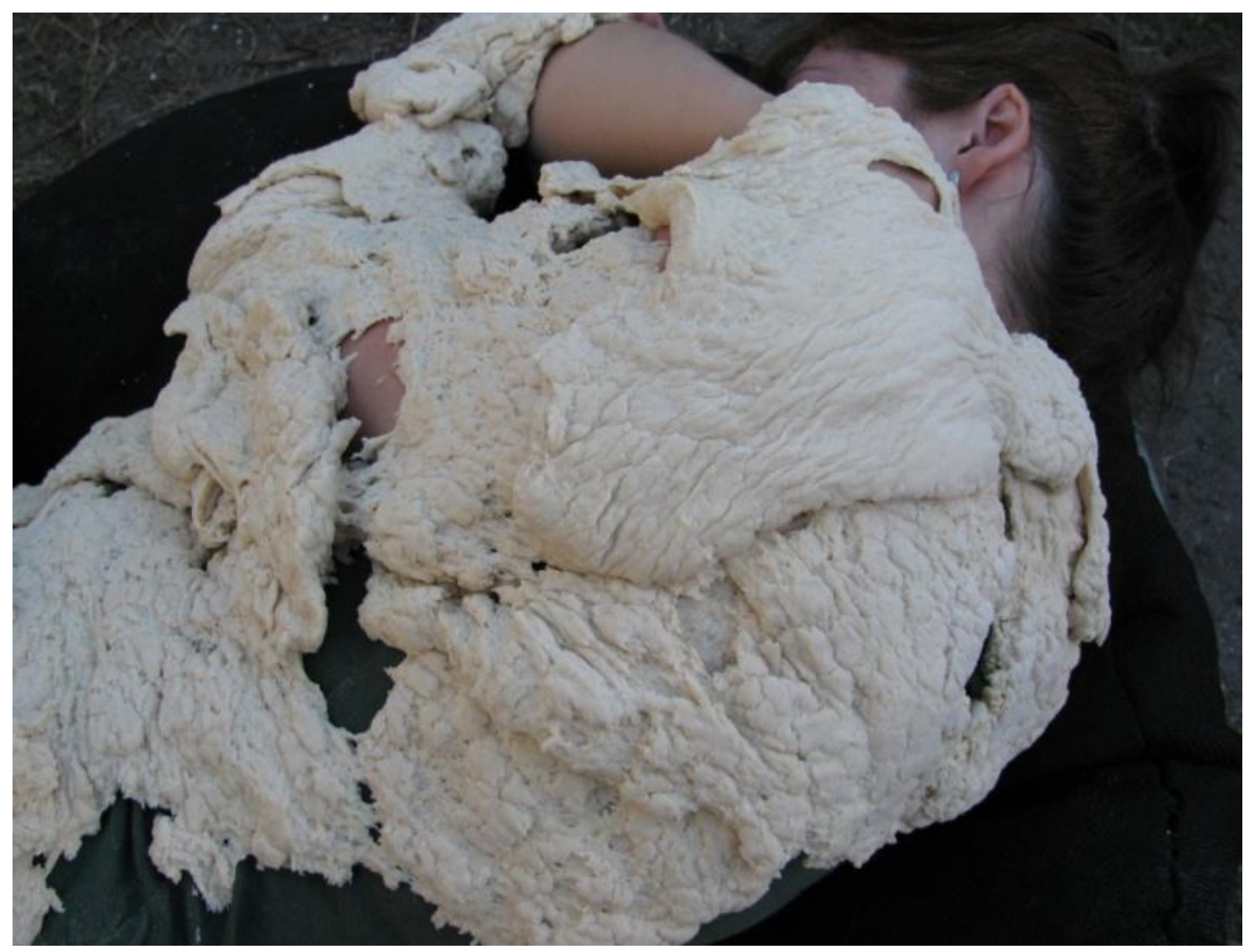

Figura 2: Adriani Araujo. Coberta, 2012. photoperformance. massa de pão crua sobre o corpo. 89,5 X $55 \mathrm{~cm}$. Fonte: acervo digital da artista. 


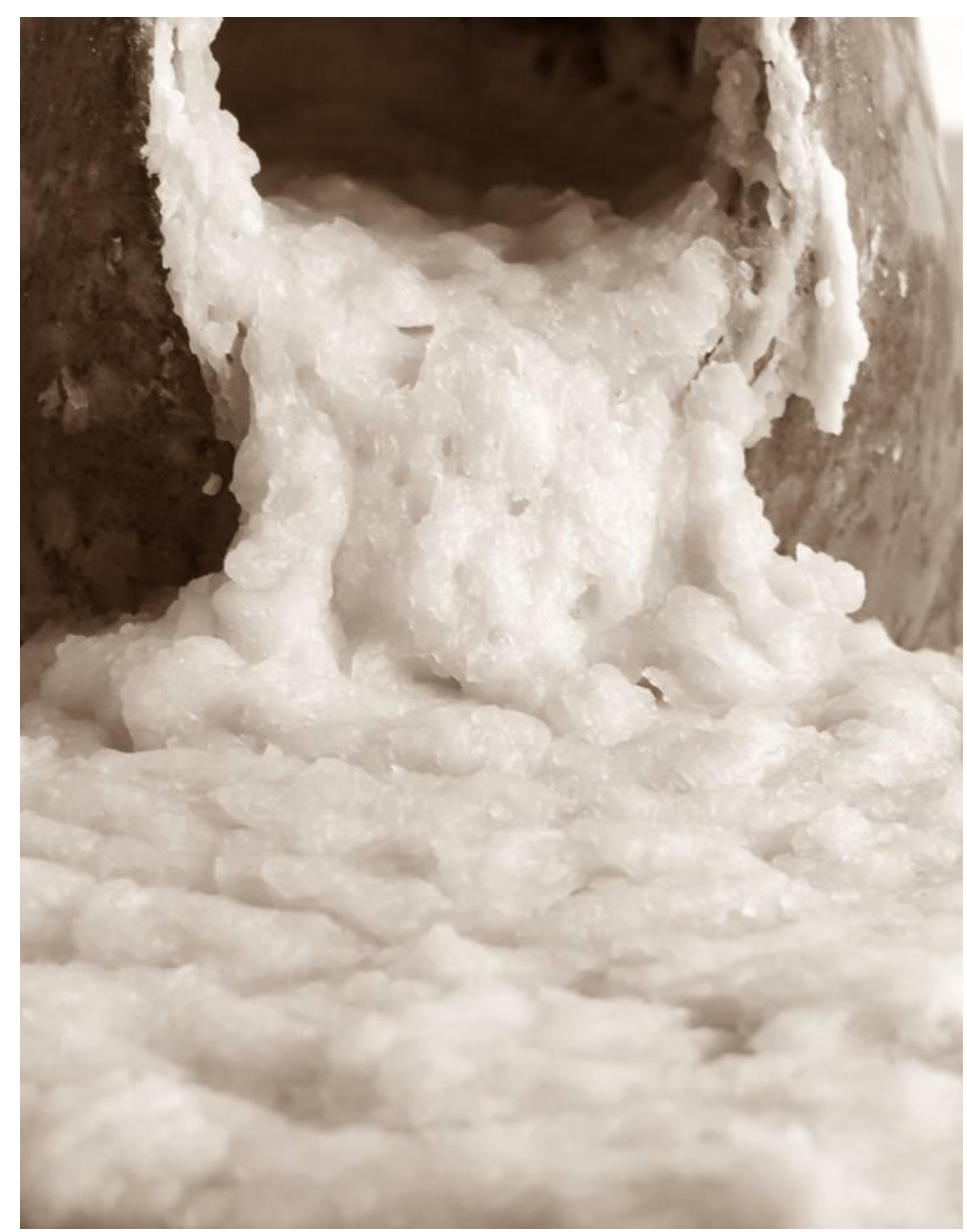

Figura 3: Adriani Araujo. Para Sartre sobre o Viscoso, 2013/2014. fotografia. 150 x $120 \mathrm{~cm}$. Fonte: www.adrianiaraujo.com.br

Nestas fotografias existe uma postura tátil da matéria, na figura 2 ela se adere, molda aquele corpo, cobrindo-o e criando um abrigo. Na figura 3 a matéria se expande para fora daquele continente, e quando transborda, deixa seu rastro e suas marcas. Podemos observar que nestas imagens como no vídeo aqui apresentado, estamos partindo de algo, que na intimidade da imagem, já nos narra um tempo de passagem e tatilidades desta matéria. O estímulo aqui pensado, portanto vem pela ideia de um dispositivo possível de ativar os sentidos, fora destas imagens.

Este estímulo se dá potencialmente pela condição viscosa da matéria que, ao se aderir ao corpo, objeto ou superfícies, cria uma zona tátil aparentemente irreversível. Uma das características da matéria viscosa é sua capacidade de se unir ao outro, de tomar tudo aquilo que toca como seu. Partindo de uma dualidade, em contato com algo, a matéria viscosa cria uma unidade reconfigurada. Neste sentido, o viscoso pode ser pensado como uma característica háptica do tato. 
Explora-se o que é, ou em que é que consiste, essa fisicalidade que faz uso da tecnologia. Mediada por imagens sintéticas digitais ou analógicas, a memória, a consciência e a percepção distanciam-se do 'real' e centram-se apenas na percepção subjetiva do eu individual da máquina física, principalmente nas suas respostas, necessidades, captações e estimulações mais diretamente físicas e corporais. (CASTELLO BRANCO, 2013, p. 513)

Se pensarmos novamente aquela massa que escorre sobre a imagem estática, numa tentativa subjetiva de reconstituir aquela arquitetura, este acréscimo visual de uma certa textura viscosa e a ausência anunciada no vídeo, é um instrumento óptico por excelência, resgatando a memória deste corpo acionando pelo dispositivo háptico. $\mathrm{O}$ vídeo como ausência recupera a falta do toque, do tato, resgatando o corpo que sente através do movimento e da sequência das imagens.

\section{Considerações Finais}

Estas são algumas ideias iniciais, para esta pesquisa que busca um aprofundamento nos estudos sobre a imagem digital e seus desdobramentos, de como ela é percebida e inserida no contexto atual na área da pesquisa e na área da produção artística em numa busca da permanência do sentido perante uma materialidade adjacente e não palpável.

Resgatar os sentidos pela imagem e também um corpo que de algum modo se anula quando capturado ou apresentado nos meios digitais pelo conceito de háptico, permite dar sequência substancial a esta pesquisa, que, neste momento, procura compreender a condição da matéria viscosa no vídeo e na fotografia. A possibilidade de uma matéria - na imaterialidade da imagem técnica - se dá especialmente por esta nova ordem perceptiva que a autora Castello Branco nos apresenta.

É na mudança de parâmetro para o virtual que a busca por um corpo se faz necessária, quando é possível compreender que a imagem não pode mais estar confinada num pensamento ocularcêntrico. O incorpóreo da imagem possibilita esta passagem pelas sensações num processo perceptivo que retoma e reconstitui um corpo e toda sua materialidade atribuída, mesmo que subjetivamente, é evidente a existência de um corpo resignificado. 


\section{REFERÊNCIAS}

ARAUJO, Adriani. Para Sartre sobre o Viscoso, 2013/2014. Disponível em: <http://www.adrianiaraujo.com.br/fotografia.php>. Acesso em: 18 dez. 2016.

BATAILLE, Georges. Documentos. Caracas: Monte Avila, 1969.

CASTELLO BRANCO, Patrícia Silveirinha. Imagem, Corpo, Tecnologia - A função háptica das novas imagens tecnológicas. Lisboa: Fundação Calouste Gulbenkian, 2013.

MERLEAU-PONTY, Maurice. Fenomenologia da Percepção. São Paulo: Martins Fontes, 2011. 